\title{
Predictors of acute intracranial hemorrhage and recurrence of chronic subdural hematoma following burr hole drainage
}

\section{FuMei Chen}

Zhejiang University School of Medicine First Affiliated Hospital

\section{Ke Wang}

Shanghai Tenth People's Hospital

\section{KangLi Xu}

Zhejiang University School of Medicine First Affiliated Hospital

\section{Li Wang}

Zhejiang University School of Medicine Sir Run Run Shaw Hospital

\section{TianXiang Zhan}

Zhejiang University School of Medicine First Affiliated Hospital

\section{Fei Cheng}

Zhejiang University School of Medicine First Affiliated Hospital

\section{Hao Wang}

Zhejiang University School of Medicine First Affiliated Hospital

\section{Zuo-Bing Chen}

Zhejiang University School of Medicine First Affiliated Hospital

\section{Liang Gao}

Shanghai Tenth People's Hospital

Xiaofeng Yang ( $\nabla$ zjcswk@zju.edu.cn )

Zhejiang University School of Medicine First Affiliated Hospital https://orcid.org/0000-0003-0994-5118

\section{Research article}

Keywords: chronic subdural hematoma; acute intracranial hemorrhage; recurrence; burr hole drainage; intraoperative irrigation

Posted Date: March 2nd, 2020

DOI: https://doi.org/10.21203/rs.2.19037/v3

License: (c) (1) This work is licensed under a Creative Commons Attribution 4.0 International License. Read Full License 
Version of Record: A version of this preprint was published at BMC Neurology on March 13th, 2020. See the published version at https://doi.org/10.1186/s12883-020-01669-5. 


\section{Abstract}

Background To investigate predictors of postoperative acute intracranial hemorrhage (AlH) and recurrence of chronic subdural hematoma (CSDH) after burr hole drainage. Methods A multicenter retrospective study of patients who underwent burr hole drainage for CSDH between January 2013 and March 2019. Results A total of $448 \mathrm{CSDH}$ patients were enrolled in the study. CSDH recurrence occurred in 60 patients, with a recurrence rate of $13.4 \%$. The mean time interval between initial burr hole drainage and recurrence was $40.8 \pm 28.3$ days. Postoperative AlH developed in 23 patients, with an incidence of $5.1 \%$. The mean time interval between initial burr hole drainage and postoperative AlH was $4.7 \pm 2.9$ days. Bilateral hematoma, hyperdense hematoma and anticoagulant drug use were independent predictors of recurrence in the multiple logistic regression analyses. Preoperative headache was an independent risk factor of postoperative AlH in the multiple logistic regression analyses, however, intraoperative irrigation reduced the incidence of postoperative $\mathrm{AlH}$. Conclusions This study found that bilateral hematoma, hyperdense hematoma and anticoagulant drug use were independently associated with CSDH recurrence. Clinical presentation of headache was the strongest predictor of postoperative $\mathrm{AlH}$, and intraoperative irrigation decreased the incidence of postoperative $\mathrm{AlH}$.

\section{Introduction}

Chronic subdural hematoma (CSDH) is one of the most common types of intracranial hemorrhage; however, its pathogenic mechanism remains unclear. The incidence of CSDH is $~ 3.4-5 / 100000$ per year in the general population and 60-80/100 000 per year in those aged $\geq 65$.[1-5] The treatment is often surgical evacuation, using techniques such as twist-drill craniotomy and burr hole drainage (BHD) or craniotomy. BHD is the most widely used technique, and has a satisfactory outcome, but has a CSDH recurrence rate of 4-38\%.[6-12] Several studies have revealed that predictors of CSDH recurrence following surgical evacuation include age, sex, antiplatelet or anticoagulation therapy, Glasgow Coma Scale (GCS), diabetes mellitus, hypertension, bilateral hematoma, preoperative hematoma size, midline shift, hematoma density, intraoperative irrigation, type of surgery and postoperative air collection, however, these results are inconsistent.[7, 13-19] The more controversial risk factors include surgery type and intraoperative irrigation. $[9,10,20-22]$ Previous reports have shown a CSDH mortality rate of 1.8-32\%. $[6,23]$

Surgical complications, such as irritability, wound infection and acute intracranial hemorrhage (AlH), occur at a rate of $0-38 \%$.[24-26] AlH, in particular, can cause severe neurological dysfunction, leading to a poor prognosis. However, the mechanism is still unclear and there is limited information on risk factors associated with AlH following surgery for $\mathrm{CSDH}$. Some previous studies have evaluated recurrence risk following CSDH surgery using only a single or few predictors, however, the majority of these were singlecenter retrospective studies and lacked interaction between other variables and confounding factors. It is, therefore, important to identify the clinical and perioperative risk factors associated with AlH and CSDH recurrence following BHD surgery. In this multi-center retrospective study we evaluated the clinical factors 
associated with postoperative AlH and CSDH recurrence, to determine an optimal perioperative management strategy for BHD with or without irrigation in $\mathrm{CSDH}$ patients.

\section{Methods}

We retrospectively analyzed the medical records of all patients diagnosed with CSDH at the Department of Neurosurgery, the First Affiliated Hospital, College of Medicine, Zhejiang University, Hangzhou, China between September 2015 and March $2019(n=315)$, and the Department of Neurosurgery of Shanghai Tenth People's Hospital, Shanghai, China between January 2013 and May $2016(n=133)$. The patients were diagnosed by computed tomography (CT) or magnetic resonance imaging (MRI).

\section{Inclusion and exclusion criteria}

The inclusion criteria were as follows: all patients were diagnosed with CSDH by CT or MRI; and initially underwent BHD with or without irrigation at one of the two institutions. Exclusion criteria included: CSDH that was treated conservatively or by surgical methods other than BHD (such twist-drill craniotomy and formal craniotomy with excision of subdural membrane); any other intracranial pathologies or intracranial surgery, such as ventriculoperitoneal shunt, epidural hematoma, parenchymal hemorrhage, intraventricular hemorrhage or ischemic insult; and recurrent CSDH.

\section{Definitions}

In this study, we defined CSDH as subdural hematoma that could be treated with BHD. We defined postoperative recurrence of $\mathrm{CSDH}$ as a subsequent radiographic discharge following the primary treatment, with re-bleeding and/or increased size of the subdural hematomas on the operated side, with or without any clinical presentation. AlH was identified as a hyperdense lesion in the ventricle, brain parenchyma, subarachnoid, subdural space or epidural space, visible on CT scan during hospitalization, and accompanied by neurological deterioration. Chronic intracranial hemorrhage $(\mathrm{ClH})$ in this study refers to cerebral hemorrhage other than recurrent $\mathrm{CSDH}$ or $\mathrm{AlH}$.

The hematoma was classified as hypodense [<30 Hounsfield units (HU)], isodense $(30-60 \mathrm{HU})$, hyperdense $(>60 \mathrm{HU})$, or mixed density based on the density difference of the hematoma and the brain parenchyma. Patients with bilateral CSDH of different types were attributed according to which reflected the greater bleeding tendency.

Surgical evacuation of CSDH was carried out when the following indications were observed:

1. Unilateral or bilateral CSDH with maximum thickness $>10 \mathrm{~mm}$ and/or midline shift $>7 \mathrm{~mm}$;

2. CSDH of any thickness causing mass effect, midline shift, or neurological signs and symptoms, such as focal deficit, and mental status changes;

3. Progressive increase in size of CSDH as observed through a series of CT or MRI scans. 
In bilateral $\mathrm{CSDH}$, the decision to evacuate one or both sides was generally made based on hematoma size and neurological symptoms. (i) Unilateral evacuation of bilateral CSDH: when the maximum diameter of the CSDH on the operation side was $>10 \mathrm{~mm}$, when the contralateral hematoma was $<10 \mathrm{~mm}$ thick, and when the laterality of neurological symptoms could only be attributed to the thicker hematoma. (ii) Bilateral evacuation of bilateral CSDH: both sides received the same treatment in a single operation.

\section{Surgical procedures and general management}

In all cases, a single burr hole was made under anesthesia. Local or general anesthetic was selected depending on the patient's general status and ability to co-operate. A 4-5 cm vertical skin incision was made at the superior temporal line near the coronal suture or at the point of maximum thickness of the CSDH. A 1.5-2 cm craniotomy was performed. After opening the dura and outer membrane of the hematoma, a soft silicon tube was inserted into the subdural space through the burr hole overlying the large part of the subdural cavity, and tunneled for a minimum of $5 \mathrm{~cm}$ away from the scalp incision. Irrigation was not carried out in all surgeries. If carried out, irrigation was with $0.9 \%$ normal saline via the tube, until the output was clear. The drain was connected to a soft collection bag and the drainage tube was removed when there was no more drainage fluid. The patient stayed in bed until the drain was removed. If CT scan showed that subdural collections remained in the hematoma cavity after the operation, the patient was treated with urokinase, according to the surgeon's preference. CT scanning indicated if the affected brain region showed sufficient re-expansion or when the amount decreased to $<50 \mathrm{ml}$ per day.

All patients had their anticoagulant or antiplatelet status optimized prior to surgery, ensuring a preoperative international normalized ratio (INR) between 0.8 and 1.2. It was managed in various ways depending on the type of anticoagulant treatment. Agents used to reverse anticoagulant or antiplatelet medications were vitamin $\mathrm{K} 1$, thrombocytes, blood plasma, tranexamic acid, prothrombin complex concentrate, and desmopressin analogs. Antiplatelet or anticoagulant agents were usually re-started 1 month from the day of surgery.

Following CSDH diagnosis, some patients were given atorvastatin (20 mg per night) prior to the operation. The decision to give the patient preoperative atorvastatin was made by the neurosurgeon. In general, atorvastatin was discontinued for at least 1 month after surgery or based on follow-up imaging. All patients were followed-up for at least 12 months.

\section{Data collection}

Demographic, clinical and radiographic data were collected using a standardized case report form and the information was added to a database. The following data were included: gender, age, history of anticoagulant or antiplatelet, head trauma event, GCS score on admission, medical history (e.g., hypertension, diabetes), preoperative main clinical symptoms (e.g., headache, dizziness), operation side (unilateral, unilateral evacuation of bilateral CSDH, bilateral evacuation of bilateral CSDH), hematoma density characteristics on CT (hyperdense, hypodense, mixed density, isodense), hematoma maximal 
thickness (preoperative hematoma thickness on the axial cut that showed the maximal diameter), midline shift, anesthesia method, intraoperative irrigation (non-irrigation versus irrigation), duration of drainage (days), urokinase injection after operation, complications (including acute intracranial bleeding, fever $>38^{\circ} \mathrm{C}$, seizure, irritability, poor wound healing and intracranial infection), time interval between initial operation and recurrence (days), time interval between initial operation and bleeding (days), and hospitalization time (days). All CT interpretations and measurements were made by a neurosurgeon and recorded after corroborating with the neuroradiologist's report.

\section{Statistical analyses}

SPSS software (version 16.0) was used for the statistical analysis.

Continuous data are expressed as the mean \pm standard deviation (SD) and categorical data are expressed as the median value (IQR). Univariable (Student t-test and the Mann-Whitney U-test), bivariable (Chi-square) and multivariable (multiple logistic regression) analyses were performed to determine which, if any, of the studied variables were associated risk factors of CSDH recurrence and AlH. The variables with $\mathrm{P}<0.1$ in the univariate analysis were included in the multivariate model. Statistical significance was defined as P-value $<0.05$.

\section{Results}

\section{Baseline clinical characteristics of patients}

A total of 448 patients (354 males, 94 females) were included in the analysis. The mean age was $68.1 \pm 12.4$ years (range: $14-98$ years). CSDH recurrence occurred in 60 (13.4\%) patients, including 26 with unilateral $\mathrm{BDH}$ evacuation, 11 with unilateral evacuation of bilateral $\mathrm{CSDH}$, and 23 with bilateral evacuation of bilateral CSDH. Complications occurred in 122 patients (27.2\%), including 23 (5.1\%) with AlH (16 patients with unilateral evacuation, five with unilateral evacuation of bilateral CSDH, and two with bilateral evacuation of bilateral CSDH). One patient died (mortality rate $=0.2 \%$ ). The mean duration of hospitalization time was $14.0 \pm 5.5$ days (range: $3-42$ days). Patient information is provided in Table 1 .

\section{Analysis of patients with recurrence}

Sixty patients (53 males, seven females) experienced CSDH recurrence following the initial BHD. The mean age was $69.6 \pm 10.8$ years (range: $31-88$ years). The mean time interval between initial BHD and recurrence was $40.8 \pm 28.3$ days (range: $12-180$ days).

Univariate analysis (Table 2$)$ showed that risk factors including anticoagulant drugs $(P=0.038)$, density of hematoma $(P=0.009)$, operation side $(P<0.001)$, and atorvastatin administration $(P=0.021)$ were significantly related to $\mathrm{CSDH}$ recurrence. Unilateral or bilateral evacuation of bilateral CSDH were not significantly correlated with $\mathrm{CSDH}$ recurrence following $\mathrm{BHD}(2.5 \%$ versus $5.1 \%, \mathrm{P}=0.707)$. Although there was no significant correlation between gender and recurrence $(P<0.1)$, it was included in the 
multivariate analysis according to our multivariate inclusion analysis criteria. Other variables that were not significantly correlated with CSDH recurrence are shown in Table 2.

In the multivariate logistic regression model, bilateral hematoma [Odds ratio (OR), 2.563; $95 \%$ confidence interval $(\mathrm{Cl}), 1.439-4.563 ; \mathrm{P}=0.001]$, mixed density $(\mathrm{OR}, 0.433 ; 95 \% \mathrm{Cl}, 0.229-0.818 ; \mathrm{P}=0.010$, hyperdense as reference) and anticoagulant drugs $(\mathrm{OR}, 4.309 ; 95 \% \mathrm{Cl}, 1.244-14.923 ; \mathrm{P}=0.021)$ were significantly associated with CSDH recurrence. Other variables not significantly associated with CSDH recurrence are detailed in Table 3.

\section{Analysis of patients with acute intracranial hemorrhage}

Twenty-three patients ( 15 males, eight females) experienced postoperative AlH. The mean age was $68.5 \pm$ 11.5 years (range: $42-87$ years). The mean time interval between initial BHD and postoperative AlH was $4.7 \pm 2.9$ days (range: $1-10$ days).

Univariate analysis indicated that preoperative headache $(P=0.046)$, preoperative hematoma thickness $(P=0.043)$ and intraoperative irrigation $(P=0.020)$ were significantly related to postoperative AlH (Table 4). Operation side $(P=0.683)$ was not significantly related to postoperative $A l H$, and there was no significant difference in the incidence of postoperative AlH between unilateral or bilateral evacuation of bilateral $\operatorname{CSDH}(1.1 \%$ versus $0.4 \%, P=0.052)$. Other variables with $P>0.1$ in the univariate analysis are shown in Table 4.

Multivariate analysis showed that preoperative headache $(\mathrm{OR}, 3.053 ; 95 \% \mathrm{Cl}, 1.181-7.890 ; \mathrm{P}=0.021)$ and intraoperative irrigation $(\mathrm{OR}, 0.289 ; 95 \% \mathrm{Cl}, 0.114-0.735 ; \mathrm{P}=0.009)$ were significantly associated with postoperative $\mathrm{AlH}$. Other variables not significantly associated with postoperative AlH or CSDH recurrence are shown in Table 5.

\section{Discussion}

$\mathrm{CSDH}$ is one of the most commonly treated neurosurgical disorders and BHD is a universal surgical treatment. $[11,18,27]$ The rate of $\mathrm{CSDH}$ recurrence following BHD is $4-38 \%$ and the complications rate is $0-38 \% .[6-12,24,26]$ In this study, we found the CSDH recurrence rate after $\mathrm{BDH}$ was $13.4 \%$ and the complication rate was $27.2 \%$. Of the 122 patients with complications, 23 had postoperative $\mathrm{AlH}(5.1 \%$ incidence). Pang et al. similarly reported an incidence of postoperative AlH of 4.57\%.[25] According to the literature, the mortality rate due to $\mathrm{CSDH}$ is $1.8-32 \%$, however, in this study, only one patient died of respiratory failure, giving a lower mortality rate of $0.2 \%$.[6,23] Comparing our results with previous studies, our definition of $\mathrm{CSDH}$, postoperative recurrence of $\mathrm{CSDH}$ and postoperative $\mathrm{AlH}$ are in accordance with medical norms and logic.

CSDHs are usually unilateral, but do present as bilateral in $~ 9.2-34.9 \%$ of cases. [5, 28-30] However, not all patients with bilateral CSDH warrant evacuation of both sides at initial presentation. The major determinants of unilateral or bilateral evacuation are preoperative maximal thickness, the degree of 
midline shift, and lateralized clinical symptoms, followed by surgical treatment of only the largest or the symptomatic hematoma, leaving the other hematoma non-operated.[31] In our study, 154 patients (34.4\%) had bilateral CSDH. Fifty-four (12.1\%) had unilateral evacuation and 100 (22.3\%) were evacuated bilaterally. Previous studies have shown that simultaneous bilateral decompression in bilateral CSDH reduces complications and the rate of $\mathrm{CSDH}$ recurrence, however, others have not corroborated this result. [31-33] In our study, there was no significant difference between the rate of CSDH recurrence and incidence of $\mathrm{AlH}$ following unilateral or bilateral evacuation in bilateral $\mathrm{CSDH}$.

The recurrence rate in unilateral CSDH is lower than that of bilateral CSDH, making bilateral hematoma a risk factor for CSDH recurrence.[16, 19] This could be due to poor brain re-expansion in bilateral CSDH compared to unilateral CSDH, which may result in a brain parenchymal shift, tearing of the blood vessels, postoperative pneumocephalus and cerebrospinal fluid accumulation in the hematoma cavity, leading to a higher recurrence rate.[19, 34, 35] Another theory is that patients with bilateral CSDH tend to have a history of brain atrophy, which leads to poor re-expansion, resulting in a higher recurrence rate.[19, 35] In our study, bilateral hematoma was found to be a risk factor for postoperative recurrence of CSDH, but was not a risk factor for postoperative $\mathrm{AlH}$. Whether the brain re-expansion theory or the brain atrophy theory were correct will require time to accumulate results. In our study, the mean time interval $(4.7 \pm 2.9$ days) between initial surgery and postoperative AlH was significantly lower than the mean time interval (40.8 \pm 28.3 days) between initial surgery and postoperative recurrence.

Some studies have reported that male sex is an independent risk factor of CSDH recurrence, and that males likely have more trauma and more frequent complications than females. However, other studies have suggested that gender is not associated with CSDH recurrence.[13, 36] In our study, 295 patients had a history of trauma, including 233 males and 62 females. According to multivariate logistic regression analysis, there was no significant correlation between gender and $\mathrm{CSDH}$ recurrence. To date, no literature has reported the relationship between gender and postoperative $\mathrm{AlH}$. We found that gender was not significantly associated with postoperative $\mathrm{AlH}$.

The clinical presentation of CSDH varies from asymptomatic to headache, limb weakness, incontinence, etc. According to our study, preoperative headache is an independent risk factor for postoperative $\mathrm{AlH}$. When CSDH presents as a clinical manifestation of headache, it indicates a higher intracranial pressure and a secondary cerebral blood flow reduction in the deep cerebral regions, causing blood vessels to spasm and increasing the risk of vascular accidents.[37] Thus, when blood flow in the brain changes or intracranial pressure changes significantly in a short period of time, blood vessels rupture, resulting in bleeding.

Many studies suggest that preoperative hematoma density is associated with CSDH recurrence, and hyperdense hematoma is an independent risk factor for CSDH recurrence. $[13,38]$ In present study, although nearly $1 / 3$ of the patients had hyperdense imaging findings, according to our clinical experience and our definition of CSDH, neurosurgeons evaluated patients with subdural hematoma no matter what the density of subdural hematoma on imaging, once they were able to be treated with BHD, these patients 
could be managed as patients with CSDH. In our study, hyperdense hematoma were more prone to CSDH recurrence than mixed density $(\mathrm{OR}, 0.433 ; 95 \% \mathrm{Cl}, 0.229-0.818 ; \mathrm{P}=0.010$, hyperdense as reference). The relationship between hematoma density and postoperative AlH has not been reported in the literature. In our study, hematoma density was not significantly associated with postoperative AlH. We suspect that when hyperdense hematoma are compared with the other three types of hematoma density, repeated microhemorrhages from the immature capillary network in the outer membrane take place and accumulate over time, causing CSDH recurrence.[38]

Preoperative hematoma thickness has been reported as an independent risk factor for CSDH recurrence. [7] It is thought that hematoma thickness has an increased tendency to recur because the subdural space is larger than a small lesion postoperatively.[7, 36] As hematoma thickness is related to many factors, such as age, midline shift and brain atrophy, it may not be a useful predictor of CSDH recurrence and postoperative AlH. However, other studies have shown no significant relationship between hematoma thickness and CSDH recurrence,[13,39] and the relationship between hematoma thickness and postoperative AlH has not been reported. In our study, the hematoma thickness of 20mm was selected as a threshold, compared with the trauma subdural hematoma guidelines threshold of $10 \mathrm{~mm}$, there were two reasons. First, a part of the patients were non-traumatic chronic subdural hematomas; second, according to our clinical experience, when the thickness of hematoma is between $10 \mathrm{~mm}$ and $20 \mathrm{~mm}$, some patients had no obvious clinical manifestations and did not require surgical treatment. According to the results, there was no significant relationship between hematoma thickness and CSDH recurrence or postoperative AlH.

Our results showed that anticoagulant drug use is an independent risk factor for CSDH recurrence. Antiplatelet drugs did not increase the CSDH recurrence rate following BHD. Similarly, a recent systematic study showed that anticoagulant drugs increased re-bleeding on the operation side of CSDH, but antiplatelet therapy did not.[40] However, this result is controversial as in other studies, antiplatelets or anticoagulants were not associated with CSDH recurrence.[16, 36, 41] The authors speculated that the reason for this finding may be that the patients were not adequately anticoagulated, especially in the nonrecurrence group. At present, only one study has reported that anticoagulants or antiplatelet drugs do not increase the incidence of postoperative AlH.[25] Similar to our results, we suspect that it may be the result offset caused by insufficient sample size. Therefore, a large sample clinical trial is necessary to verify this result.

Atorvastatin is another management option, which may be used alone or in conjunction with surgery. Several studies have shown that CSDH is caused by impaired angiogenesis in the neomembrane and localized inflammation, and that atorvastatin improves angiogenesis and reduces the inflammatory response.[42,43] A randomized control study showed that the oral administration of atorvastatin is safe and effective in treating CSDH, and promotes the resolution of hematoma.[44] A prospective study showed that atorvastatin administration may decrease the risks of CSDH recurrence.[45] However, in our study, atorvastatin did not reduce the rate of $\mathrm{CSDH}$ recurrence, nor did it reduce the incidence of postoperative AlH. We suspect that different research methods may lead to varying results. 
In our study, intraoperative saline irrigation was based on the surgeon's preference. Some studies have shown that intraoperative saline irrigation of the hematoma cavity does not improve the incidence of postoperative AlH and CSDH recurrence.[25, 46] According to our results, intraoperative irrigation does not reduce the risk of $\mathrm{CSDH}$ recurrence, however, it does reduce the incidence of postoperative $\mathrm{AlH}$. We speculate that BHD for $\mathrm{CSDH}$ without irrigation significantly reduces intracranial pressure for a short period of time. The abrupt decrease in intracranial pressure may cause further damage to the intracranial blood vessels and lead to acute intracranial bleeding.

Our study had some limitations. First, our study is a retrospective design, which usually produces a risk of bias. Based on our data and personal communication with neurosurgeons in each participating department, neurosurgeons not only choose the surgical method based on symptoms and hematoma size, but also according to their preferences. For example, the use of a single burr hole, the $1.5-2 \mathrm{~cm}$ craniotomy and whether to irrigate is based on neurosurgeon preference. However, according to literature reports and our results, the selection of these surgical methods did not result in significant differences postoperative complications in total and recurrence rates[25]. Second, in the multivariate model, although ideally more stringent criteria for variable inclusion in the model would be applied in lieu of $p<0.1$. However, it may lead to too few variables and too many confounding factors, which will have a greater impact on the results.

\section{Conclusions}

In this study, we evaluated predictors of CSDH recurrence and postoperative AlH following BHD in a multicenter retrospective study of patients with CSDH. We identified bilateral hematoma, hyperdense hematoma and anticoagulant drugs as independent risk factors for recurrence of $\mathrm{CSDH}$. Preoperative headache is an independent risk factor for postoperative $\mathrm{AlH}$, and intraoperative irrigation reduces the incidence of postoperative AlH. Further prospective multi-center studies will be required to evaluate these findings.

\section{Abbreviations}

CSDH: chronic subdural hematoma; AlH: acute intracranial hemorrhage; $\mathrm{ClH}$ : Chronic intracranial hemorrhage; BHD: burr hole drainage; CT: computed tomography; MRI: magnetic resonance imaging; GCS: Glasgow Coma Scale.

\section{Declarations}

\section{Acknowledgment}

Not applicable.

\section{Authors' contributions}


XFY, LG, ZBC, HW designed research, performed research, analyzed data. FMC, KW, KLX collected data, analyzed the data and drafted the manuscript. LW, TXZ, FC collected and analyzed the data. All authors checked and agreed on the final manuscript.

\section{Funding}

This study was supported the National Natural Science Foundation of China (No.81470052).

\section{Availability of data and materials}

The datasets used during the current study are available from the corresponding author on reasonable request.

\section{Ethics approval and consent to participate}

This study was approved by the ethics committees of the two medical centers. The requirement for obtaining informed consent from patients was waived because the data sets were anonymous.

\section{Consent for publication}

Not applicable.

\section{Competing interests}

The authors declare that they have no competing interests.

\section{References}

1. Santarius T, Hutchinson PJ: Chronic subdural haematoma: time to rationalize treatment? $\mathrm{Br} J$ Neurosurg 2004, 18(4):328-332.

2. Asghar M, Adhiyaman V, Greenway MW, Bhowmick BK, Bates A: Chronic subdural haematoma in the elderly-a North Wales experience. J R Soc Med 2002, 95(6):290-292.

3. Chronic subdural hematoma in elderly people: present status on Awaji Island and epidemiological prospect. 1992.

4. Karibe $H$, Kameyama M, Kawase M, Hirano T, Kawaguchi T, Tominaga T: [Epidemiology of chronic subdural hematomas]. No Shinkei Geka 2011, 39(12):1149-1153.

5. Hsieh CT, Su IC, Hsu SK, Huang CT, Lian FJ, Chang CJ: Chronic subdural hematoma: Differences between unilateral and bilateral occurrence. J Clin Neurosci 2016, 34:252-258.

6. Kolias AG, Chari A, Santarius T, Hutchinson PJ: Chronic subdural haematoma: modern management and emerging therapies. Nat Rev Neurol 2014, 10(10):570-578.

7. Chon KH, Lee JM, Koh EJ, Choi HY: Independent predictors for recurrence of chronic subdural hematoma. Acta Neurochir (Wien) 2012, 154(9):1541-1548. 
8. Berghauser Pont LM, Dammers R, Schouten JW, Lingsma HF, Dirven CM: Clinical factors associated with outcome in chronic subdural hematoma: a retrospective cohort study of patients on preoperative corticosteroid therapy. Neurosurgery 2012, 70(4):873-880; discussion 880.

9. Ducruet AF, Grobelny BT, Zacharia BE, Hickman ZL, DeRosa PL, Andersen KN, Sussman E, Carpenter A, Connolly ES, Jr.: The surgical management of chronic subdural hematoma. Neurosurg Rev 2012, 35(2):155-169; discussion 169.

10. Lega BC, Danish SF, Malhotra NR, Sonnad SS, Stein SC: Choosing the best operation for chronic subdural hematoma: a decision analysis. J Neurosurg 2010, 113(3):615-621.

11. Lind CR, Lind CJ, Mee EW: Reduction in the number of repeated operations for the treatment of subacute and chronic subdural hematomas by placement of subdural drains. J Neurosurg 2003, 99(1):44-46.

12. Miranda LB, Braxton E, Hobbs J, Quigley MR: Chronic subdural hematoma in the elderly: not a benign disease. J Neurosurg 2011, 114(1):72-76.

13. Fujitani S, Ishikawa O, Miura K, Takeda Y, Goto H, Maeda K: Factors predicting contralateral hematoma growth after unilateral drainage of bilateral chronic subdural hematoma. J Neurosurg 2017, 126(3):755-759.

14. Rust T, Kiemer N, Erasmus A: Chronic subdural haematomas and anticoagulation or anti-thrombotic therapy. J Clin Neurosci 2006, 13(8):823-827.

15. Tahsim-Oglou Y, Beseoglu K, Hänggi D, Stummer W, Steiger H-J: Factors predicting recurrence of chronic subdural haematoma: the influence of intraoperative irrigation and low-molecular-weight heparin thromboprophylaxis. Acta Neurochirurgica 2012, 154(6):1063-1068.

16. Torihashi K, Sadamasa N, Yoshida K, Narumi O, Chin M, Yamagata S: Independent predictors for recurrence of chronic subdural hematoma: a review of $\mathbf{3 4 3}$ consecutive surgical cases. Neurosurgery 2008, 63(6):1125-1129; discussion 1129.

17. Song DH, Kim YS, Chun HJ, Yi HJ, Bak KH, Ko Y, Oh SJ: The Predicting Factors for Recurrence of Chronic Subdural Hematoma Treated with Burr Hole and Drainage. Korean Journal of Neurotrauma 2014, 10(2).

18. Motiei-Langroudi R, Stippler M, Shi S, Adeeb N, Gupta R, Griessenauer CJ, Papavassiliou E, Kasper EM, Arle J, Alterman RL et al: Factors predicting reoperation of chronic subdural hematoma following primary surgical evacuation. J Neurosurg 2018, 129(5):1143-1150.

19. Han MH, Ryu JI, Kim CH, Kim JM, Cheong JH, Yi HJ: Predictive factors for recurrence and clinical outcomes in patients with chronic subdural hematoma. J Neurosurg 2017, 127(5):1117-1125.

20. Mondorf Y, Abu-Owaimer M, Gaab MR, Oertel JM: Chronic subdural hematoma-craniotomy versus burr hole trepanation. Br J Neurosurg 2009, 23(6):612-616.

21. Wang W, Liu H, Yang J: Burr hole craniostomy irrigation with and without drainage during surgical treatment of chronic subdural hematoma: A retrospective study of $\mathbf{8 7}$ cases. Turk Neurosurg 2017.

22. Yuan Y, Wang QP, Cao YL, Zhang H, Burkutally MSN, Budryte K, Xiong N: Burr hole drainage and burr hole drainage with irrigation to treat chronic subdural hematoma: A systematic review and meta- 
analysis. Medicine (Baltimore) 2018, 97(33):e11827.

23. Wang S, Ma Y, Zhao X, Yang C, Gu J, Weng W, Hui J, Mao Q, Gao G, Feng J: Risk factors of hospital mortality in chronic subdural hematoma: A retrospective analysis of 1117 patients, a single institute experience. J Clin Neurosci 2019, 67:46-51.

24. Rohde V, Graf G, Hassler W: Complications of burr-hole craniostomy and closed-system drainage for chronic subdural hematomas: a retrospective analysis of $\mathbf{3 7 6}$ patients. Neurosurgical Review 2002, 25(1-2):89-94.

25. Pang CH, Lee SE, Kim CH, Kim JE, Kang H-S, Park C-K, Paek SH, Kim CH, Jahng T-A, Kim JW et al: Acute intracranial bleeding and recurrence after bur hole craniostomy for chronic subdural hematoma. Journal of Neurosurgery 2015, 123(1):65-74.

26. Bucher B, Maldaner N, Regli L, Sarnthein J, Serra C: Standardized assessment of outcome and complications in chronic subdural hematoma: results from a large case series. Acta Neurochirurgica 2019, 161(7):1297-1304.

27. Ramachandran R, Hegde T: Chronic subdural hematomas-causes of morbidity and mortality. Surg Neurol 2007, 67(4):367-372; discussion 372-363.

28. Park HS, Park ES, Park JB, Kwon SC, Lyo IU, Kim MH, Sim HB: Chronic Subdural Hematomas: Comparison between Unilateral and Bilateral Involvement. Korean J Neurotrauma 2014, 10(2):55-59.

29. Huang YH, Yang KY, Lee TC, Liao CC: Bilateral chronic subdural hematoma: what is the clinical significance? Int J Surg 2013, 11(7):544-548.

30. Tsai TH, Lieu AS, Hwang SL, Huang TY, Hwang YF: A comparative study of the patients with bilateral or unilateral chronic subdural hematoma: precipitating factors and postoperative outcomes. $J$ Trauma 2010, 68(3):571-575.

31. Motiei-Langroudi R, Thomas AJ, Ascanio L, Alturki A, Papavassiliou E, Kasper EM, Arle J, Alterman RL, Ogilvy CS, Stippler M: Factors Predicting the Need for Surgery of the Opposite Side After Unilateral Evacuation of Bilateral Chronic Subdural Hematomas. Neurosurgery 2018.

32. Andersen-Ranberg NC, Poulsen FR, Bergholt B, Hundsholt T, Fugleholm K: Bilateral chronic subdural hematoma: unilateral or bilateral drainage? J Neurosurg 2017, 126(6):1905-1911.

33. Sadrolhefazi A, Bloomfield SM: Interhemispheric and bilateral chronic subdural hematoma. Neurosurgery Clinics of North America 2000, 11(3):455-463.

34. Kung WM, Hung KS, Chiu WT, Tsai SH, Lin JW, Wang YC, Lin MS: Quantitative assessment of impaired postevacuation brain reexpansion in bilateral chronic subdural haematoma: possible mechanism of the higher recurrence rate. Injury 2012, 43(5):598-602.

35. Shen J, Gao Y, Li Q, Ge R, Wang Q, Jiang X, Shao X: Risk Factors Predicting Recurrence of Bilateral Chronic Subdural Hematomas after Initial Bilateral Evacuation. World Neurosurg 2019.

36. Bartek J, Sjåvik K, Kristiansson H, Ståhl F, Fornebo I, Förander P, Jakola AS: Predictors of Recurrence and Complications After Chronic Subdural Hematoma Surgery: A Population-Based Study. World Neurosurgery 2017, 106:609-614. 
37. Okuyama T, Saito K, Fukuyama K, Yamamoto K, Morimoto M, Aburano T: [Clinical study of cerebral blood flow in bilateral chronic subdural hematoma measured by $99 \mathrm{mTc}$-HMPAO SPECT]. No To Shinkei 2000, 52(8):709-714.

38. Lin CC, Lu YM, Chen TH, Wang SP, Hsiao SH, Lin MS: Quantitative assessment of post-operative recurrence of chronic subdural haematoma using mean haematoma density. Brain Inj 2014, 28(8):1082-1086.

39. Nakaguchi $\mathrm{H}$, Tanishima $\mathrm{T}$, Yoshimasu $\mathrm{N}$ : Factors in the natural history of chronic subdural hematomas that influence their postoperative recurrence. J Neurosurg 2001, 95(2):256-262.

40. Nathan S, Goodarzi Z, Jette N, Gallagher C, Holroyd-Leduc J: Anticoagulant and antiplatelet use in seniors with chronic subdural hematoma Systematic review. Neurology 2017, 88(20):1889-1893.

41. Okano A, Oya S, Fujisawa N, Tsuchiya T, Indo M, Nakamura T, Chang HS, Matsui T: Analysis of risk factors for chronic subdural haematoma recurrence after burr hole surgery: optimal management of patients on antiplatelet therapy. Br J Neurosurg 2014, 28(2):204-208.

42. Xu M, Chen P, Zhu X, Wang C, Shi X, Yu B: Effects of Atorvastatin on Conservative and Surgical Treatments of Chronic Subdural Hematoma in Patients. World Neurosurgery 2016, 91:23-28.

43. Tang R, Shi J, Li X, Zou Y, Wang L, Chen Y, Yan R, Gao B, Feng H: Effects of Atorvastatin on Surgical Treatments of Chronic Subdural Hematoma. World Neurosurg 2018, 117:e425-e429.

44. Jiang R, Zhao S, Wang R, Feng H, Zhang J, Li X, Mao Y, Yuan X, Fei Z, Zhao Y et al: Safety and Efficacy of Atorvastatin for Chronic Subdural Hematoma in Chinese Patients. JAMA Neurology 2018, 75(11).

45. Liu H, Luo Z, Liu Z, Yang J, Kan S: Atorvastatin May Attenuate Recurrence of Chronic Subdural Hematoma. Front Neurosci 2016, 10:303.

46. Almenawer SA, Farrokhyar F, Hong C, Alhazzani W, Manoranjan B, Yarascavitch B, Arjmand P, Baronia $\mathrm{B}$, Reddy $\mathrm{K}$, Murty $\mathrm{N}$ et al: Chronic subdural hematoma management: a systematic review and metaanalysis of 34,829 patients. Ann Surg 2014, 259(3):449-457.

\section{Tables}




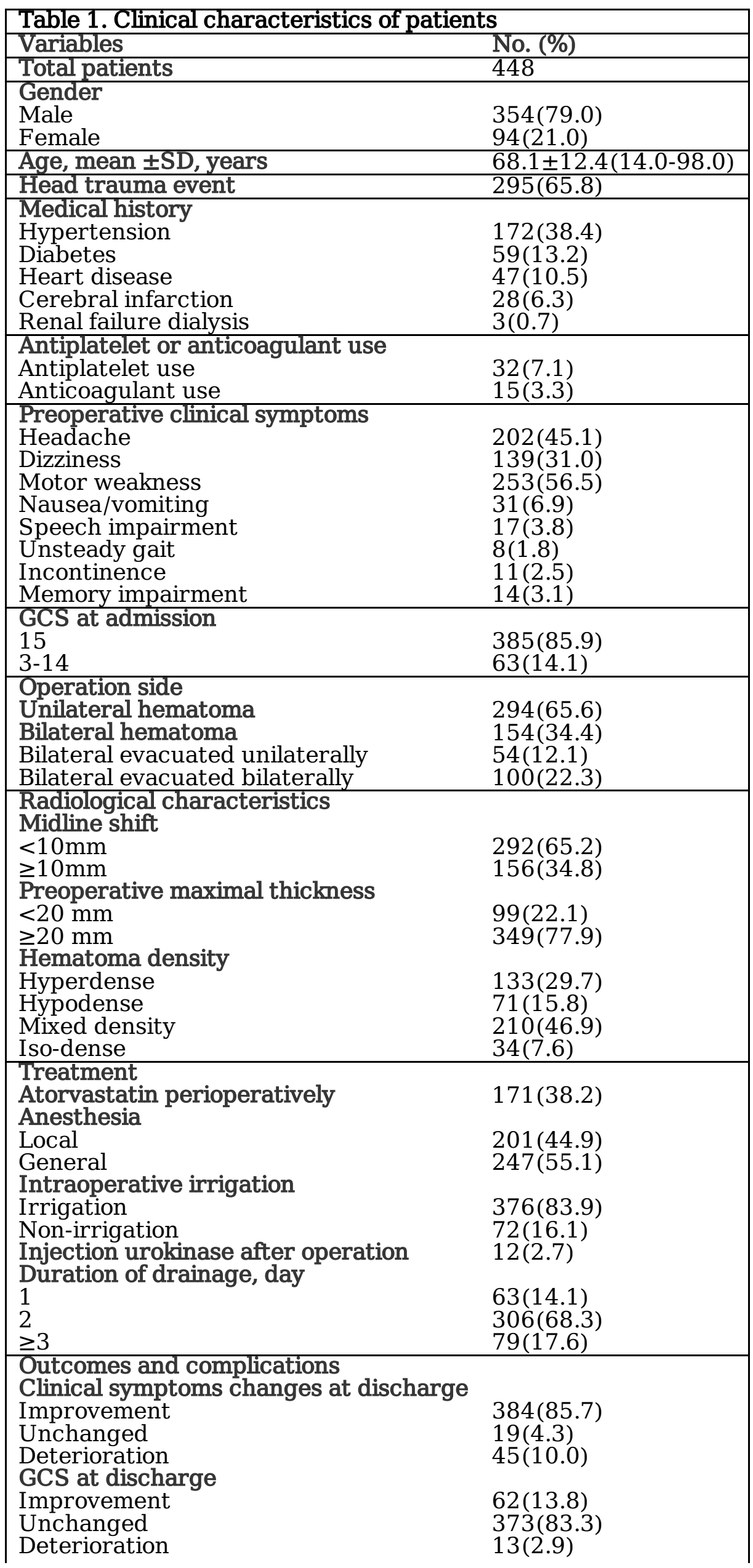


Complications

Fever

Irritability

Poor wound healing

Seizure

Deep vein thrombosis

$\mathrm{AIH}$

$\mathrm{CIH}$

Recurrence

Mortality

Hospitalization time, mean $\pm \mathrm{SD}$, days
$122(27.2)$

69(15.4)

19(4.3)

$1(0.2)$

$2(0.4)$

$1(0.2)$

23(5.1)

7(1.6)

$60(13.4)$

$1(0.2)$

GCS: Glasgow Coma Scale; AIH: acute intracranial hemorrhage; CIH: chronic intracranial hemorrhage 


\begin{tabular}{|c|c|c|c|}
\hline Variables & Recurrence & No recurrence & P Value \\
\hline Patients & $60(\%)$ & $388(\%)$ & \multirow{4}{*}{0.057} \\
\hline Gender & & & \\
\hline Male & $53(88.3)$ & $301(77.6)$ & \\
\hline Female & $7(11.7)$ & $87(22.4)$ & \\
\hline Age (years) & & & \multirow[t]{3}{*}{0.576} \\
\hline $\begin{array}{l}<70 \\
>70\end{array}$ & $30(50)$ & $209(53.9)$ & \\
\hline $\begin{array}{l}\geq 70 \\
\text { Head trauma event }\end{array}$ & $\frac{30(50)}{35(502)}$ & $179(46.1)$ & \\
\hline Medical history & $5(50.5)$ & $200(01.0)$ & \multirow{6}{*}{$\begin{array}{l}0.575 \\
0.389 \\
0.093 \\
0.404 \\
0.351\end{array}$} \\
\hline Hypertension & $25(41.7)$ & $147(37.9)$ & \\
\hline Diabetes & $10(16.7)$ & $49(12.6)$ & \\
\hline Heart disease & $10(16.7)$ & $37(9.5)$ & \\
\hline Cerebral infarction & $5(8.3)$ & $23(5.9)$ & \\
\hline Renal failure dialysis & $1(1.7)$ & $2(0.5)$ & \\
\hline Antiplatelet or anticoagulant drugs & & & \multirow{3}{*}{$\begin{array}{l}0.415 \\
0.038\end{array}$} \\
\hline Antiplatelet drugs & $6(10.0)$ & $26(6.7)$ & \\
\hline Anticoagulant drugs & $5(8.3)$ & $10(2.6)$ & \\
\hline \multicolumn{4}{|l|}{ The main symptoms } \\
\hline Headache & $26(43.3)$ & $176(45.4)$ & \multirow{8}{*}{$\begin{array}{l}0.769 \\
0.628 \\
0.598 \\
0.408 \\
0.486 \\
0.292 \\
1.000 \\
0.704 \\
\end{array}$} \\
\hline Dizziness & $17(28.3)$ & $122(31.4)$ & \\
\hline Motor weakness & $32(53.3)$ & $221(57.0)$ & \\
\hline Nausea/vomiting & $2(3.3)$ & $29(7.5)$ & \\
\hline Speech impairment & $3(5.0)$ & $14(3.6)$ & \\
\hline Unsteady gait & $2(3.3)$ & $6(1.5)$ & \\
\hline Incontinence & $1(1.7)$ & $10(2.6)$ & \\
\hline Memory decline & $1(1.7)$ & $13(3.4)$ & \\
\hline \multirow{3}{*}{$\begin{array}{l}\text { GCS at admission } \\
15 \\
3-14\end{array}$} & & & \multirow[t]{3}{*}{0.566} \\
\hline & $53(88.3)$ & $332(85.6)$ & \\
\hline & $7(11.7)$ & $56(14.4)$ & \\
\hline \multicolumn{3}{|l|}{ Operation side } & \multirow[t]{3}{*}{$\mathrm{P}<0.001$} \\
\hline Unilateral hematoma & $26(43.3)$ & $270(69.6)$ & \\
\hline Bilateral hematoma & $34(56.7)$ & $118(30.4)$ & \\
\hline \multicolumn{3}{|l|}{ Radiological characteristics } & \multirow{4}{*}{0.975} \\
\hline Midline shift & & & \\
\hline$<10 \mathrm{~mm}$ & $39(65.0)$ & $253(65.2)$ & \\
\hline$\geq 10 \mathrm{~mm}$ & $21(35.0)$ & $135(34.8)$ & \\
\hline \multirow{2}{*}{$\begin{array}{l}\text { Preoperative maximal thickness } \\
<20 \mathrm{~mm} \\
\geq 20 \mathrm{~mm}\end{array}$} & & & \multirow[t]{2}{*}{0.154} \\
\hline & $9(15.0)$ & $90(23.2)$ & \\
\hline $\begin{array}{l}\geq 20 \mathrm{~mm} \\
\text { Hematoma density }\end{array}$ & $51(85.0)$ & $298(76.8)$ & \multirow{5}{*}{0.009} \\
\hline Hyper-dense & $29(48.3)$ & $104(26.8)$ & \\
\hline Hypo-dense & $7(11.7)$ & $64(16.5)$ & \\
\hline Mixed density & $21(35.0)$ & $189(48.7)$ & \\
\hline Iso-dense & $3(5.0)$ & $31(8.0)$ & \\
\hline \multicolumn{4}{|l|}{ Treatment } \\
\hline Atorvastatin perioperatively & $31(51.7)$ & $140(36.1)$ & \\
\hline Anesthesia & & & 0.982 \\
\hline Local & $27(45.0)$ & $174(44.8)$ & \\
\hline General & $33(55.0)$ & $214(55.2)$ & \\
\hline Intraoperative irrigation & $49(81.7)$ & $327(84.3)$ & 0.608 \\
\hline Injection urokinase after operation & $3(5.0)$ & $9(2.3)$ & 0.208 \\
\hline Duration of drainage, day & & & 0.842 \\
\hline 1 & $9(15.0)$ & $54(14.0)$ & \\
\hline 2 & $42(70.0)$ & $264(68.0)$ & \\
\hline$\geq 3$ & $9(15.0)$ & $70(18.0)$ & \\
\hline Complications & & & \\
\hline Fever & $5(8.3)$ & $64(16.5)$ & 0.103 \\
\hline Irritability & $4(6.7)$ & $15(3.9)$ & 0.303 \\
\hline Poor wound healing & $1(1.7)$ & 0 & \\
\hline Seizure & $1(1.7)$ & $1(0.26)$ & 0.250 \\
\hline Deep vein thrombosis & 0 & $1(0.26)$ & - - \\
\hline $\mathrm{AIH}$ & 0 & $23(5.9)$ & - - \\
\hline Hospitalization time, mean $\pm S D$, days & $14.0 \pm 6.4$ & $14.0 \pm 5.4$ & 0.905 \\
\hline
\end{tabular}

GCS: Glasgow Coma Scale; AIH: acute intracranial hemorrhage. 


\begin{tabular}{|c|c|c|c|c|}
\hline le 3. Multivariate logistic regressio & nalysis of fa & for recurr & $\overline{\mathrm{DH}}$ & OR: Odds ratio \\
\hline Risk factors & OR & $95 \% \mathrm{CI}$ & Pvalue & confiden \\
\hline Gender & 2.139 & $0.897-5.099$ & 0.086 & \\
\hline Operation side (Unilateral vs Bilateral) & 2.563 & $1.439-4.563$ & 0.001 & terval. \\
\hline $\begin{array}{l}\text { Hematoma density } \\
\text { Hyperdense }\end{array}$ & Reference & Reference & Reference & \\
\hline $\begin{array}{l}\text { Hypodense } \\
\text { Mixed density }\end{array}$ & 0.428 & $0.173-1.061$ & 0.067 & \\
\hline $\begin{array}{l}\text { Mixed density } \\
\text { Iso-dense }\end{array}$ & $\begin{array}{l}0.433 \\
0.364\end{array}$ & $\begin{array}{l}0.229-0.818 \\
0.101-1.311\end{array}$ & $\begin{array}{l}0.010 \\
0.122\end{array}$ & \\
\hline Atorvastatin perioperatively & 1.634 & $0.918-2.908$ & 0.095 & \\
\hline Anticoagulant drugs & 4.309 & $1.244-14.923$ & 0.021 & \\
\hline
\end{tabular}




\begin{tabular}{|c|c|c|c|}
\hline Variables & AIH & No AIH & P Value \\
\hline Patients & $23(\%)$ & $425(\%)$ & \\
\hline Gender & & & 0.113 \\
\hline Male & 15(65.2) & $339(79.8)$ & \\
\hline Female & $8(34.8)$ & $86(20.2)$ & \\
\hline Age (years) & & & 0.908 \\
\hline$<70$ & $12(52.2)$ & $227(53.4)$ & \\
\hline$\geq 70$ & $11(47.8)$ & $198(46.6)$ & \\
\hline Head trauma event & $14(60.9)$ & $281(66.1)$ & 0.605 \\
\hline Medical history & & & \\
\hline Hypertension & $12(52.2)$ & $160(37.6)$ & 0.163 \\
\hline Diabetes & $2(8.7)$ & $57(13.4)$ & 0.754 \\
\hline Heart disease & $1(4.3)$ & $46(10.8)$ & 0.494 \\
\hline Cerebral infarction & $1(4.3)$ & $27(6.4)$ & 1.00 \\
\hline Renal failure dialysis & $0(0)$ & $3(0.7)$ & - \\
\hline Antiplatelet or anticoagulant drugs & & & \\
\hline Antiplatelet drugs & $3(13.0)$ & $29(6.8)$ & 0.221 \\
\hline Anticoagulant drugs & $1(4.3)$ & $14(3.3)$ & 0.552 \\
\hline Preoperative clinical symptoms & & & \\
\hline Headache & $15(65.2)$ & $187(44.0)$ & 0.046 \\
\hline Dizziness & $0(0)$ & $139(32.7)$ & \\
\hline Motor weakness & $14(60.9)$ & $239(56.2)$ & 0.662 \\
\hline Nausea/vomiting & $2(8.7)$ & $29(6.9)$ & 0.668 \\
\hline Speech impairment & $0(0)$ & $17(4.0)$ & \\
\hline Unsteady gait & $1(4.3)$ & $7(1.6)$ & 0.346 \\
\hline Incontinence & $0(0)$ & $11(2.6)$ & -- \\
\hline Memory decline & $0(0)$ & $14(3.3)$ & - - \\
\hline GCS at admission & & & 0.756 \\
\hline 15 & $21(91.3)$ & $364(85.6)$ & \\
\hline $3-14$ & $2(8.7)$ & $61(14.4)$ & \\
\hline Operation side & & & 0.683 \\
\hline Unilateral hematoma & $16(69.6)$ & $278(65.4)$ & \\
\hline Bilateral hematoma & $7(30.4)$ & $147(34.6)$ & \\
\hline Radiological characteristics & & & \\
\hline Midline shift & & & 0.367 \\
\hline$<10 \mathrm{~mm}$ & $17(73.9)$ & $275(64.7)$ & \\
\hline$\geq 10 \mathrm{~mm}$ & $6(26.1)$ & $150(35.3)$ & 0 \\
\hline $\begin{array}{l}\text { Preoperative maximal thickness } \\
<20 \mathrm{~mm}\end{array}$ & 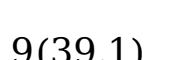 & 900 & 0.043 \\
\hline$\geq 20 \mathrm{~mm}$ & $14(60.9)$ & $335(78.8)$ & \\
\hline Hematoma density & & & 0.924 \\
\hline Hyper-dense & $7(30.4)$ & $126(29.6)$ & \\
\hline Hypo-dense & $4(17.4)$ & $67(15.8)$ & \\
\hline Mixed density & $10(43.5)$ & $200(47.1)$ & \\
\hline Iso-dense & $2(8.7)$ & $32(7.5)$ & \\
\hline Treatment & & & \\
\hline Atorvastatin perioperatively & $9(39.1)$ & $162(38.1)$ & 0.922 \\
\hline Anesthesia & & & 0.249 \\
\hline $\begin{array}{l}\text { Local } \\
\text { General }\end{array}$ & $\begin{array}{l}13(56.5) \\
10(43.5)\end{array}$ & $\begin{array}{l}188(44.2) \\
237(55.8)\end{array}$ & \\
\hline Intraoperative irrigation & $15(65.2)$ & $361(84.9)$ & 0.020 \\
\hline Injection urokinase after operation & $0(0)$ & $12(2.8)$ & \\
\hline Duration of drainage, day & & & 0.307 \\
\hline 1 & $1(4.3)$ & $62(14.6)$ & \\
\hline$\geq 3$ & $\begin{array}{l}19(82.7) \\
3(13.0)\end{array}$ & $\begin{array}{l}287(67.5) \\
76(17.9)\end{array}$ & \\
\hline
\end{tabular}

GCS: Glasgow Coma Scale; AIH: acute intracranial hemorrhage.

\begin{tabular}{|lccc|}
\hline \multicolumn{4}{|c|}{ Table 5. Multivariate logistic regression analysis of factors related to postoperative AIH } \\
\hline Risk factors & OR & $95 \%$ CI & P value \\
\hline Headache & 3.053 & $1.181-7.890$ & 0.021 \\
\hline Preoperative maximal thickness & 0.543 & $0.219-1.351$ & 0.189 \\
\hline Intraoperative irrigation & 0.289 & $0.114-0.735$ & 0.009 \\
\hline
\end{tabular}

OR: Odds ratio; $\mathrm{CI}$ : confidence interval. 
Page 20/20 